\title{
Research on Problems and Countermeasures of New Employment Form in the New Period
}

\author{
Deming Lei ${ }^{1, \text { a }}$ \\ School of law and Economics, Wuhan University of Science \\ and Technology Wuhan \\ Wuhan, Hubei, China
}

\author{
Hongzhen $\operatorname{Lin}^{2, \mathrm{~b}^{*}}$ \\ School of Hengda Management, Wuhan University of Science \\ and Technology Wuhan \\ Wuhan, Hubei, China \\ *Corresponding author: Hongzhen Lin
}

\begin{abstract}
With the continuous development of market economy, people's employment choices are showing a diversified status, and the new employment form has become a new trend. The purpose of this paper is to study the countermeasures to promote the development of new employment form in China. The object of this study is the problem of new employment pattern and the corresponding countermeasures. The research methods are literature research and investigation. The research contents are the causes of the new employment pattern, the types and characteristics of the new employment pattern, the existing problems and the corresponding countermeasures. The conclusion of the study is that it is necessary to perfect corresponding laws and regulations to improve security system of the new employment form, and improve the corresponding management to promote healthy development of the new employment form.
\end{abstract}

Keywords-new forms of employment; flexibility; labor relations; social security

\section{INTRODUCTION}

The new employment pattern is a new special way that combines the workers with the means of production. New forms of employment are usually based on new technologies such as Internet and artificial intelligence, accompanied by new business models such as platform economy and sharing economy. Employment flexibility is an inevitable requirement for the operation and development of market economy. It requires the flexible transfer of labor resources to more efficient industries. Laborers' working time and space become more flexible, which improves the efficiency of value production and realization. While the traditional industrial relationship structure and adjustment are taking shape, various new informal employment relationships are also developing [1]. The emergence of new forms of employment adapts to this changing trend and is more flexible. The new flexible employment model is gradually changing the situation of informal employment in China, which has a positive and negative impact on the operation of the existing economic society and the behavior of the economic subject [2]. Technological progress and industrial structure are decisive factors, especially the new round of change is reshaping traditional employment patterns and labor relations. In recent years, with the gradual upgrading of production technology, the original employment concept and employment system have changed rapidly, resulting in many new employment models and new occupations, which have a profound impact on the pattern of the labor market and the allocation of resources [3]. In the dilemma of flexibility and security in the new employment pattern, the situation of protecting workers' rights and interests is becoming more and more complex, showing new characteristics, and putting forward new requirements for the government as well as market mechanism to protect workers' rights and interests [4].

\section{REASONS FOR THE NEW EMPLOYMENT FORM}

\section{A. Technological Progress}

"New employment form" is the reflection of the new economic form in the field of employment, which is generated by the new technology in the new era. It is a new employment form which has not been completely transformed into an independent new form by the extension of traditional industries under the conditions of the Internet. It has gradually become a new employment form leading the community of human destiny[5]. Technological progress is the main manifestation of the development of social productive forces. Changes in technological conditions of production can bring fundamental changes to the direct production process, thus leading to changes in employment patterns. With the wide application of the new generation of information and communication technology in the economic and social fields, new technologies, new economy and new formats are developing rapidly in China and new forms of employment are emerging. The new employment pattern is a new employment mode under the new technology, which will play an active role in achieving higher quality and full employment, but it also challenges the traditional labor relations and social security system [6].

\section{B. Changes In Production Organization}

Production organization is the place where people's activities, objects and means of work are combined. On the other hand.It is the way and method to organize people's labor ability. It constitutes the social conditions of the labor process. The innovation of production organization forms reflects the new changes and requirements of the labor process. It can make production technology more efficient and control labor force, thus leading to changes in employment patterns. Enterprise production organization may become a platform connecting supply and demand. The new format of Internet economy and new employment form just adopt the 
organizational form of "platform + individual" to explore a feasible way for enterprise production organization innovation.

\section{ChARACTERISTICS OF THE NEW EMPLOYMENT FORM}

The new forms of employment mainly include platform entrepreneurship, multiple forms of employment and full-time employment of Internet virtual platform. They share common characteristics.

\section{A. Flexibility of Labor Mode}

Flexibility is the main feature of the new form of employment. The combination of workers and means of production is more flexible and changeable. Workers' activities are more autonomous and flexible. Labor time is fragmented. Whether as a user or as a direct producer, people can provide information and objects of labor for themselves or others at all times. The boundaries between working hours and leisure time are no longer so obvious. Fast information tools enable workers to carry out production, management and service at any time and anywhere.

\section{B. Elasticity of Labor Relations}

With the rapid development of the shared economy, network contracted labor has developed into a large-scale new employment group, and shows a distinct new employment pattern, which is mainly manifested in the platform of the employer, the high flexibility and socialization of the mode of employment, and the network restriction of the mode of employment. Non-standardization, non-equilibrium of "emphasizing performance while neglecting responsibility" in employment management, and de-labor relationship in employment relationship are the main characteristics [7]. In the new form of employment, the labor contract relationship has strong flexibility, temporary or multiple. "Individual" workers, such as online car drivers, online contract workers, etc., can freely combine with the platform they serve, often without signing a fixed labor contract. Their work tasks are flexible and changeable because of the different information they acquire, and their labor relations are characterized by the temporary characteristics of employing or self-employing.

\section{PROBLEMS IN THE NEW EMPLOYMENT FoRM}

\section{A. Difficulties in Identifying Labor Relations among Employees with New Forms}

New forms of employment emerge in the new format of the Internet economy, which is different from traditional forms of employment. The latter is mainly shaped by the industrial economy, and a set of corresponding employment, labor, social security and other institutional mechanisms have been established. Especially the deep integration of information technology and real economy, while creating new jobs, Old jobs are still being wiped out. Therefore, there are many contradictions between the development of new forms of employment and the institutional mechanism of traditional employment, which cause many social problems.

\section{B. Imperfection of relevant laws}

The protection of workers 'rights and interests in the new employment pattern first highlights the imperfection of relevant laws and regulations. At present, the new scientific and technological revolution has promoted the transformation of social production mode from Ford system to flexible accumulation system. The resulting diversification, flexibility and de-employing of labor relations are similar in form to the post-Ford negotiation and cooperation mechanism. However, the crisis and gradual disintegration of Ford system is a slow process, and the adjustment of relevant typical labor relations and laws and regulations is lagging behind. Due to the late appearance of new flexible employment personnel, the complexity of labor relations, the lack of reference cases at home and abroad, and the lack of clear legal standards, labor disputes have been frequent in recent years [8].

\section{Inadequate Social Security}

The participation rate of new flexible employees is low. Many new flexible employees with unstable employment and low income have no economic ability to participate in social security. In addition, the current law restricts the new flexible employees, and there are many obstacles in administrative management and labor supervision. There are many problems in the actual implementation of social insurance. In the aspect of endowment insurance, due to the late implementation of flexible employment endowment insurance policy and the lack of social security awareness for a long time, some older workers may exceed the legal age of payment, thus losing the rights and interests of endowment insurance. In the aspect of medical insurance, at present, compared with the unified account model, the new flexible employment model mainly aims at the serious illness. Because only the unified account and no personal account are set up, it is not close to the actual needs of the new flexible employment personnel.

\section{Relevant Management Without Keeping Pace With The Times}

New forms of employment are increasingly becoming an important channel for expanding employment, which makes the demand for public employment services more and more prominent. Public employment services are public welfare employment services provided by labor and social security departments at all levels. They are the basis for improving the quality of employment. The lack of honest management and supervision by the government on new forms of employment has affected the new ones. The healthy development of employment forms [9]. Firstly, management experience is insufficient, social insurance agencies lack personal experience for new flexible employees, and the long-accumulated experience in the process of social insurance for enterprises is difficult to continue to be competent. Especially in many areas with low informationization, new flexible employees must go to the operating machines themselves. It is inconvenient for both parties to deal with insurance premiums because of its large number of personnel and complicated procedures. 


\section{Measures to Promote the DeVElopment OF THE NEW EMPLOYMENT FORM}

A. Create a Learning Employment Mechanism Atmosphere for the whole Society

Promoting workers' knowledge and skills is an objective requirement of the new employment pattern. Under the new scientific and technological revolution, information technology industry will become the "general condition of social production process". Workers must master the basic knowledge and skills to adapt to the general conditions. This is not only limited to information technology knowledge, but also includes entrepreneurship and innovation ability, scientific and technological knowledge, humanistic literacy and many other aspects. This requires laborers to study actively, lifelong and comprehensively, but the current education mode and labor mode do not yet have such incentives and conditions. We should build a learning employment mechanism, mobilize the resources of society, enterprises and individuals, and explore a new way of combining education, employment and labor. Let learning become a kind of work, a profession, so that the combination of labor and learning, to achieve the individual development of workers and comprehensive promotion. The aim is to ensure that the speed of knowledge and skills upgrading of workers keeps pace with the speed of productivity development, and to promote the free and comprehensive development of human beings.

\section{B. Improve Relevant Laws}

We should not only continue to improve the traditional typical employment forms of labor relations, social security and other laws and regulations, but also standardize the development of new forms of employment, to prevent the emergence of flexible labor relations caused by the loss of workers' rights and interests. To establish and improve the social security system for flexible employment groups, the first thing we need to do is to improve the protection of the legitimate rights and interests of flexible employment groups to the level of law, and to protect them through the form of laws and regulations. Through the form of legislation, the state can further regulate the vague labor relations, arrange the payment of labor compensation and social security participation after the workers leave the labor contract, and further refine the flexible employment and part-time employment.

\section{Establish a Social Security System Adapting to the New Employment Form}

The state should formulate the corresponding social security system for the flexible employment groups separately, and provide the corresponding payment methods pertinently. In the process of formulating the social security insurance system, the system should be designed according to the actual income of the residents, so as to design a set of truly available for the flexible employment groups. Social security system of income. In terms of specific measures, we can adopt ways and means such as reducing the contribution rate and improving the distribution methods to stimulate flexible employees to participate in the process of social security [10].

In terms of safeguard content, we should not only implement complete coverage and bottom-line thinking, but also adhere to the principle of coexistence of voluntary and compulsory, facing risks for new flexible employees.Larger social insurance forces them to participate in insurance. For insurance with less risk, they adhere to the principle of voluntariness. Policies encourage and guide them to participate in insurance. The existing framework and tools of labor law analysis to analyze and solve the problem of labor social security under the background of new technology[11].

\section{Increase Relevant Management of the New Employment Form}

We need to improve the consultation and coordination mechanism involving the government, trade unions and enterprises, and build a harmonious labor relationship. On the one hand, the government should restrict employers' torts by administrative means, such as requiring uniform wage standards, vacation standards and working hours standards; on the other hand, it should play the role of trade unions in safeguarding the legitimate rights and interests of workers and innovate the form of trade unions to carry out collective bargaining. Trade unions can be established by region or industry. On the one hand, local governments need to provide pre-job training services according to their employment characteristics, enhance their competitiveness, and then increase their income; on the other hand, they need to increase the financial expenditure of social insurance and set up special new types.

The Employment Promotion Fund for Flexible Employees can reduce the burden of tax and fee as much as possible through the reform of tax and fee system. The factors of macro-policy, macro-economy, platform enterprises, laborers, consumers and so on have significant effects on the atypical employment relationship for their development. We need to optimize the mediation mechanism for atypical employment relationship [12].

\section{CONCLUSION}

In the new employment pattern, the combination of workers and production materials has undergone profound changes. Employment of workers has more flexibility, autonomy and creativity, which is considered to be the mainstream form of employment in the future society. Intelligent production informationization and personalized diversification of demand objectively require high-skilled and humanistic quality of workers. With the formation of mass customization social production mode, workers get rid of direct production process and have more free time and material conditions to engage in independent and free activities. To further promote the development of new forms of employment in our country is of great significance to our economic development, social stability and people's happiness. Workers should actively learn to improve their labor skills to match the requirements of the times. The state should improve the relevant laws and management to overcome the difficulties of flexible employment groups in participating in social security, open a convenient door for more flexible employment groups to participate in social security, and protect their legitimate rights and interests. 


\section{ACKNOWLEDGEMENT}

This research was financially supported by Project Hubei Province Education Department Foundation: Study on legal guarantee for flexible employment of workers in excess capacity industry in Hubei Province. No. 17Y016.

This research was financially supported by Project research of Hubei non-profit organization research center, 2016 ,The Role And Status Of Social Organizations In The Construction Of Harmonious Labor Relations. No. HBNPO2016ZD006.

\section{REFERENCE}

[1] Changkai. Stages, characteristics and trends of labor relations with Chinese characteristics: from the perspective of international comparative labor relations [J]. Journal of Wuhan University (Philosophy and Social Sciences Edition), 2017, 70 (5): 21-29. (In Chinese)

[2] Zhang Chenggang and Zhu Huilin. The current situation and impact of new flexible employment in China's labor market [J]. China Labor,2017 (9): 22-30. (In Chinese)

[3] China Employment Promotion Association. New Employment Form [J]. China Employment, 2017 (11): 26-27. (In Chinese)

[4] Yuan Sai. Discussion on the Situation and Countermeasure of Laborers'Rights and Interests Guarantee in the New Employment Form
[J]. Journal of Hubei Second Normal University, 2017, 34 (7): 46-49. (In Chinese)

[5] Zhu Songling. New forms of employment: concepts, models and prospects [J].China Youth Social Sciences, 2018, v.37; No.196 (3) 14-20. (In Chinese)

[6] Wang Juan. New forms of employment in the context of high-quality development: connotation, impact and Development Countermeasures [J]. Academic exchanges, 2019, 300 (03): 132-142. (In Chinese)

[7] Wang Yan, Zhang Lihua. A Study on the New Employment Form of Shared Economy in China [J]. Journal of China Institute of Labor Relations, 2019 (2). 49-59. (In Chinese)

[8] Wang Wenzhen, Li Wenjing. The impact of platform economic development on China's labor relations [J]. China Labor, 2017 (1): 4-12. (In Chinese)

[9] Guo Rongli, Guo Xiuhong. Reflections on Public Employment Services from the Perspective of New Employment Form [J]. Commercial Economy, 2017 (12): 109-111. (In Chinese)

[10] Social Security Policy of Xiao Xijun's Flexible Employment Groups 2017 (10): 99. (In Chinese)

[11] Wang Quan Xing. Preliminary thoughts on the form of labor employment and labor relations under the background of "Internet +" [J]. Chinese labor, 2017 (8): 7-8. (In Chinese)

[12] Wei Wei, Yang Heqing, Wang Xin. Influencing factors and optimization of atypical employment relationship in new employment pattern [J]. Journal of China Institute of Labor Relations, 2019, 33 (1): 19-31. (In Chinese) 